Delft University of Technology

\title{
A small porous-plug burner for studies of combustion chemistry and soot formation
}

Campbell, M. F.; Schrader, P. E.; Catalano, A. L.; Johansson, K. O.; Bohlin, G. A.; Richards-Henderson, N. K.; Kliewer, C. J.; Michelsen, H. A.

DOI

10.1063/1.5016212

Publication date

2017

Document Version

Final published version

Published in

Review of Scientific Instruments

\section{Citation (APA)}

Campbell, M. F., Schrader, P. E., Catalano, A. L., Johansson, K. O., Bohlin, G. A., Richards-Henderson, N. K., Kliewer, C. J., \& Michelsen, H. A. (2017). A small porous-plug burner for studies of combustion chemistry and soot formation. Review of Scientific Instruments, 88(12), [125106].

https://doi.org/10.1063/1.5016212

Important note

To cite this publication, please use the final published version (if applicable).

Please check the document version above.

\section{Copyright}

Other than for strictly personal use, it is not permitted to download, forward or distribute the text or part of it, without the consent of the author(s) and/or copyright holder(s), unless the work is under an open content license such as Creative Commons.

\section{Takedown policy}

Please contact us and provide details if you believe this document breaches copyrights.

We will remove access to the work immediately and investigate your claim. 


\section{A small porous-plug burner for studies of combustion chemistry and soot formation}

M. F. Campbell, P. E. Schrader, A. L. Catalano, K. O. Johansson, G. A. Bohlin, N. K. Richards-Henderson, C. J. Kliewer, and H. A. Michelsen

Citation: Review of Scientific Instruments 88, 125106 (2017);

View online: https://doi.org/10.1063/1.5016212

View Table of Contents: http://aip.scitation.org/toc/rsi/88/12

Published by the American Institute of Physics

\section{Articles you may be interested in}

Design and characterization of a linear Hencken-type burner

Review of Scientific Instruments 87, 115114 (2016); 10.1063/1.4967491

Simple method to measure the refractive index of liquid with graduated cylinder and beaker

Review of Scientific Instruments 88, 125105 (2017); 10.1063/1.5001359

Note: Micro-channel array crucible for isotope-resolved laser spectroscopy of high-temperature atomic beams

Review of Scientific Instruments 88, 126101 (2017); 10.1063/1.5006457

Experiments match simulations in a multiple post reentrant cavity

Review of Scientific Instruments 88, 125104 (2017); 10.1063/1.4997626

Hybrid setup for micro- and nano-computed tomography in the hard X-ray range

Review of Scientific Instruments 88, 123702 (2017); 10.1063/1.5011042

Note: Low-temperature scanning tunneling microscope with detachable scanner and reliable transfer mechanism for tip and sample exchange

Review of Scientific Instruments 88, 126102 (2017); 10.1063/1.4997347

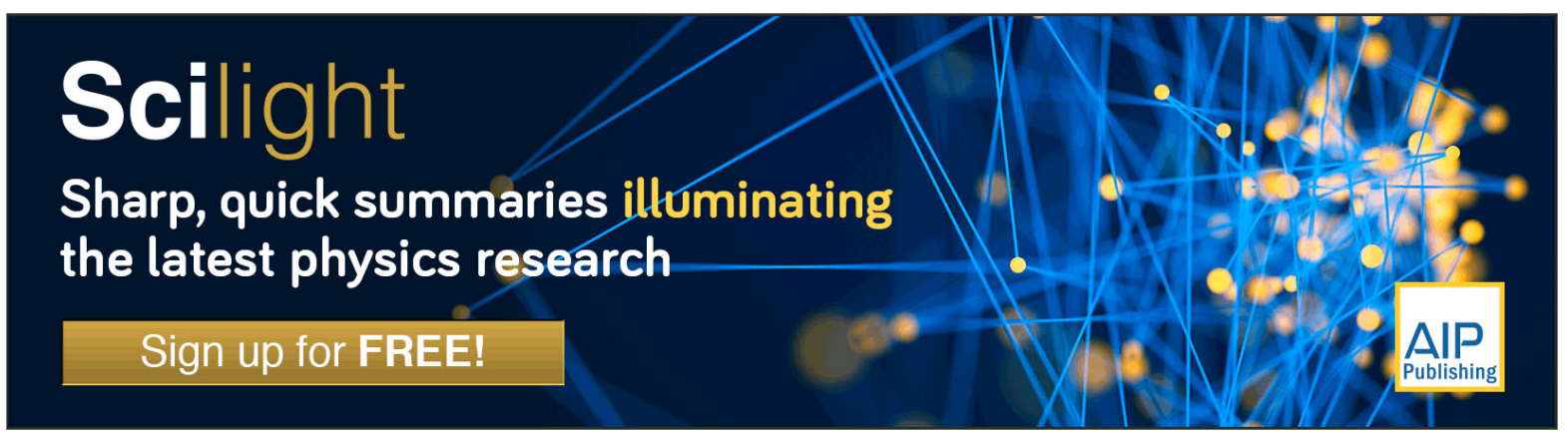




\title{
A small porous-plug burner for studies of combustion chemistry and soot formation
}

\author{
M. F. Campbell, ${ }^{1}$ P. E. Schrader, ${ }^{1}$ A. L. Catalano, ${ }^{2}$ K. O. Johansson, ${ }^{1}$ G. A. Bohlin,,${ }^{1,3}$ \\ N. K. Richards-Henderson, ${ }^{4}$ C. J. Kliewer ${ }^{1}$ and H. A. Michelsen ${ }^{1, a)}$ \\ ${ }^{1}$ Combustion Research Facility, Sandia National Laboratories, Livermore, California 94550, USA \\ ${ }^{2}$ Holthuis and Associates, Sebastopol, California 95473, USA \\ ${ }^{3}$ Department of Aerodynamics Wind Energy Flight Performance and Propulsion, \\ Delft University of Technology, Delft, The Netherlands \\ ${ }^{4}$ Chemical Sciences Division, Lawrence Berkeley National Laboratory, Berkeley, California 94720, USA
}

(Received 11 May 2017; accepted 14 November 2017; published online 8 December 2017)

\begin{abstract}
We have developed and built a small porous-plug burner based on the original McKenna burner design. The new burner generates a laminar premixed flat flame for use in studies of combustion chemistry and soot formation. The size is particularly relevant for space-constrained, synchrotronbased X-ray diagnostics. In this paper, we present details of the design, construction, operation, and supporting infrastructure for this burner, including engineering attributes that enable its small size. We also present data for charactering the flames produced by this burner. These data include temperature profiles for three premixed sooting ethylene/air flames (equivalence ratios of 1.5, 1.8, and 2.1); temperatures were recorded using direct one-dimensional coherent Raman imaging. We include calculated temperature profiles, and, for one of these ethylene/air flames, we show the carbon and hydrogen content of heavy hydrocarbon species measured using an aerosol mass spectrometer coupled with vacuum ultraviolet photoionization (VUV-AMS) and soot-volume-fraction measurements obtained using laser-induced incandescence. In addition, we provide calculated mole-fraction profiles of selected gas-phase species and characteristic profiles for seven mass peaks from AMS measurements. Using these experimental and calculated results, we discuss the differences between standard McKenna burners and the new miniature porous-plug burner introduced here. Published by AIP Publishing. https://doi.org/10.1063/1.5016212
\end{abstract}

\section{INTRODUCTION}

Soot is a pollutant that is known to have wide-ranging negative effects on air quality, human health, and global and regional climate. ${ }^{1-3}$ Despite the extent of its impact, however, there are significant gaps in understanding the underlying processes that lead to soot formation. ${ }^{4-7}$ Developing a better understanding of soot-formation pathways is important for designing, implementing, and optimizing soot-mitigation strategies. ${ }^{8-10}$

Chemical studies of soot formation are often conducted in laboratory flames. In a laminar premixed flat flame, the fuel and oxidizer are mixed prior to ignition. Burners are designed to maintain laminar flow of the fuel-oxidizer mixture to generate a steady flame that is quasi-one-dimensional with height above the burner (HAB). Perhaps the earliest description of a flat-flame burner in the literature was provided in 1949 by Powling, ${ }^{11}$ whose burner used a tube filled with glass beads and screens along with a flow-stabilizing triangular-tube matrix to achieve flow uniformity at the burner surface. Several studies made use of this or a similar design. ${ }^{12-15}$ Powling $^{11}$ also indicated the possibility of using a sintered metal disk instead of the beads and screens for flow stabilization. Several subsequent designs, sometimes referred to as Kaskan burners, used

\footnotetext{
a) Author to whom correspondence should be addressed: hamichelsen2@ gmail.com or hamiche@sandia.gov
}

a sintered bronze plug for this purpose. ${ }^{16-19}$ A modification of the Kaskan-type design is commonly known as the McKenna burner. McKenna burners consist of a circular sintered bronze or stainless steel plug through which a mixture of fuel and oxidizer flows. This premixed flow is surrounded by a coflowing co-annular shroud flow of a relatively inert gas, such as nitrogen or argon, which prevents perturbations from room air currents, entrainment of air into the flame, and generation of a diffusion flame under rich premixed conditions. ${ }^{20-22}$ Air is sometimes used as the co-flow shroud gas to generate a radially more homogeneous temperature profile by promoting formation of a diffusion flame at the edges, which counteracts the cooling effect of the shroud flow. ${ }^{23}$ A potential drawback to this approach is that soot generated from a diffusion flame tends to be more mature with a higher $\mathrm{C} / \mathrm{H}$ elemental ratio and more long-range fine-structure order, particularly in the edge region of the flame, than soot produced in a rich premixed flame. ${ }^{24}$ Thus, a premixed flame with a co-flow of air, although radially more homogeneous in temperature, may be less homogeneous in soot physical and chemical characteristics; these inhomogeneities limit the reliability of line-of-sight measurements for studies of soot formation and chemistry. A similar concept to the porous-plug burner, known as a perforated plate burner, uses a perforated metal sheet instead of a sintered plug. ${ }^{25-27}$ Characteristic features of some flatflame burners used in the literature are provided for reference in Table I. 
TABLE I. Dimensions of several flat-flame burners used in the literature.

\begin{tabular}{|c|c|c|c|c|c|c|c|c|c|}
\hline Author or company & Year & Type & $\begin{array}{l}\text { Central } \\
\text { diameter } \\
(\mathrm{mm})\end{array}$ & $\begin{array}{c}\text { Shroud } \\
\text { outer diameter } \\
(\mathrm{mm})\end{array}$ & $\begin{array}{l}\text { Overall } \\
\text { diameter } \\
(\mathrm{mm})\end{array}$ & Height (mm) & $\begin{array}{c}\text { Gas } \\
\text { delivery }\end{array}$ & $\begin{array}{c}\text { Water } \\
\text { delivery }\end{array}$ & References \\
\hline Kaskan & 1957 & Sintered plug & $38-76$ & None & Unknown & Unknown & Bottom & Bottom & 17 \\
\hline Van Maaren et al. & 1994 & Perforated plate & 30 & None & 103 & 128 & Bottom & Side & 26 \\
\hline Hartung et al. & 2006 & Perforated plate & 40 & 62 & 74 & 124 & Bottom/side & Side & 27 \\
\hline McKenna products & & Sintered plug & 60 & 66 & 116 & 65 & Bottom & Bottom & $20,28-30$ \\
\hline McKenna products & & Sintered plug & 25 & 50 & 90 & 66 & Bottom & Bottom & 19 and 31 \\
\hline Holthuis and associates & & Sintered plug & 60 & 74 & 120 & 60 & Bottom & Bottom & 23 and 32 \\
\hline This work & & Sintered plug & 38.1 & 50.8 & 76.2 & 31.75 & Side & Side & \\
\hline
\end{tabular}

Premixed, laminar, steady flat flames are advantageous in combustion studies for a variety of reasons. Because they are steady, they allow for long integration times to improve precision and detection sensitivity with smaller detection volumes and better spatial resolution. They also allow for control of the reactant mixture, which enables studies of the effects of variables, such as the carbon-to-oxygen ratio ( $\mathrm{C}: \mathrm{O}$ or $\left.R_{\mathrm{CO}}\right)$, equivalence ratio $(\phi)$, fuel type, oxygen mole fraction, or dilution. Moreover, flat-flame burners can be fired with a wide variety of fuels, including small hydrocarbon gases (e.g., hydrogen, methane, acetylene, and ethylene ${ }^{33}$ ), liquids (e.g., $n$-heptane, $n$-decane, or iso-octane ${ }^{34}$ ), and organic hazardous materials. ${ }^{20}$ Operating conditions can extend over a wide range of pressures, ranging from vacuum ${ }^{35,36}$ to several atmospheres. ${ }^{31}$ Porous metal plugs furthermore serve as flashback arrestors, preventing the flame front from entering the burner because of heat transfer losses. ${ }^{16,37}$ In addition, the boundary conditions and equations governing premixed flame propagation are simple compared to those of other systems (e.g., turbulent diffusion flames), ${ }^{38-40}$ which facilitates computational simulations. Typically, a one-dimensional structure is assumed in which, to a first approximation, properties (e.g., species mole fractions and temperature) vary only with height above the burner surface. A computationally friendly burner configuration facilitates comparisons between theory and experiment. One-dimensional flame structures also allow the use of in situ optical techniques that have long probe volumes, such as lowangle nonlinear mixing or quasi-line-of-sight techniques. ${ }^{41}$ The versatility of flat-flame burners makes them ideal for studying soot formation.

The burner described here was designed to be used in multiple diagnostic configurations. Its size is limited by an experiment that constrains the vertical height of the burner and flame to no more than $\sim 70 \mathrm{~mm}$. This experiment involves in situ measurements of soot using X-ray Raman spectroscopy (XRS) at the Stanford Synchrotron Radiation Lightsource at SLAC National Accelerator Laboratory and will be described in a later paper. Our primary objective for this paper is to detail the design, construction, and characterization of this miniature McKenna burner in order to provide a standard, canonical premixed flat-flame burner configuration and allow the combustion community to leverage our experimental results and those from groups using the same burner configuration.
We have characterized ethylene/air flames produced by this burner using several diagnostic techniques, including direct one-dimensional coherent anti-Stokes Raman spectroscopy (CARS) for temperature profiles, on-line vacuum ultraviolet photoionization aerosol mass spectrometry (VUV-AMS) for extracted-particle chemical composition, and laser-induced incandescence (LII) for soot-volume fractions. We have also calculated gas-phase species mole-fraction profiles for one ethylene/air flame for comparison with measured profiles and model validation.

\section{BURNER DESIGN}

\section{A. Burner description}

The small porous-plug burner described here (henceforth referred to as a "modified," "miniature," or "mini" McKenna burner) is similar to conventional McKenna burners in that it consists of two concentric sintered bronze plugs with outer diameters of $38.1 \mathrm{~mm}$ for the fuel/oxidizer mixture and $50.8 \mathrm{~mm}$ for the shroud, separated by a 1.14-mm-thick stainless-steel (type 304) ring (part of the housing) and surrounded by a stainless-steel enclosure (called the flange) with an overall outer diameter of $76.2 \mathrm{~mm}$ (see Fig. 1). Both the premixed-gas and shroud-gas sintered plugs are composed of bronze beads with a nominal diameter of $150 \mu \mathrm{m}$. The central plug is $16.5 \mathrm{~mm}$ thick, and the outer plug is $8.9 \mathrm{~mm}$ thick. Within the central plug is a single 25.4-mm-diameter loop of eighth-inch $(\sim 3.2 \mathrm{~mm})$ copper tube (positioned approximately $9.5 \mathrm{~mm}$ below the surface) through which cooling water flows. The use of bronze rather than stainless steel for the sintered plugs enhances heat transfer within the burner, which helps prevent overheating ${ }^{31}$ and provides a more uniform soot distribution above the burner surface in rich flames. ${ }^{32}$ An O-ring (AS 568-034 size) is used to seal the housing and the flange pieces. Mechanical drawings of this burner are provided in the supplementary material.

The premixed gas diffuses around the copper coil through the central plug, and an inert shroud gas (usually nitrogen or argon) passes through the outer plug. As pointed out by Gregor and Dreizler, ${ }^{22}$ the shroud gas serves to minimize perturbations from room air currents, ensures that the flame at the edge of the porous plug remains detached, and suppresses outer 


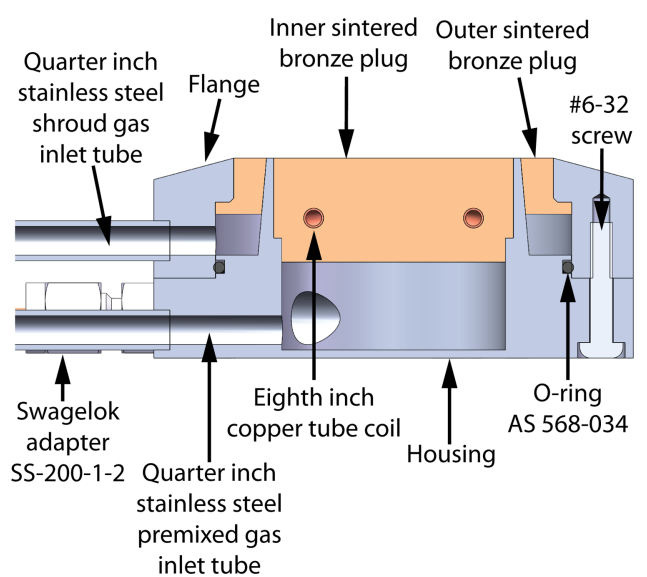

FIG. 1. Cross-sectional view of the miniature McKenna burner. Premixed gases enter through the lower quarter-inch tube and travel to the inner sintered bronze plug, and shroud gas enters through the upper tube. Cooling water at a temperature of $15{ }^{\circ} \mathrm{C}$ circulates through the copper coil, keeping the burner's temperature close to $25{ }^{\circ} \mathrm{C}$. The O-ring is used to seal the housing and the flange.

diffusion flames when operating under rich premixed conditions. Using an oxidizer, such as air, as the shroud gas allows diffusive mixing of oxidizer into the flame at the edges and increases the temperature uniformity across the burner surface ${ }^{23}$ but likely also decreases the soot uniformity across the burner surface. We use an inert gas in the shroud flow to facilitate line-of-sight optical diagnostics for soot, and we generally use nitrogen as the shroud gas to facilitate in situ diagnostics using hard X-rays. Whereas most flat-flame burners have delivered gases and temperature-regulating water through the bottom side of the burner (see Table I), the miniature McKenna burner described here has gas and water ports on its side. This change allows the total height of the burner (as measured from the base to the burner surface) to be only $31.75 \mathrm{~mm}$. However, the reduced height also constrains the volume available for in situ gas mixing and requires the use of a separate gas-mixing vessel.

As in similar designs, ${ }^{23,32}$ a circular stainless steel flame stabilization plate with a diameter equal to that of the inner sintered bronze plug $(38.1 \mathrm{~mm})$ is centered above the central plug of the burner (see Fig. 2). The distance between the plate and the bronze plug defines the maximum HAB boundary condition. Burners with $60-\mathrm{mm}$ sintered bronze plugs have a standoff distance of $20-21 \mathrm{~mm} .^{23,32,42}$ For this burner, the stabilization plate is $13.3 \mathrm{~mm}$ from the outer edge of the bronze plug, but the bronze plug has a slight bowl shape that yields a standoff distance of $13.6 \mathrm{~mm}$ in the center of the burner. The difference between center and edge standoff distances is negligible for intrusive measurements, such as those involving a sampling probe inserted into the flame. For non-intrusive laser diagnostics performed precisely along the vertical centerline of the flame, however, we account for this slight inhomogeneity in burner geometry. The standoff distance governs the time available for soot formation in the flame and has small effects on gas temperature and species profiles (see Secs. IV and S2 of the supplementary material). The temperature of the stabilization plate is monitored using a $\mathrm{K}$-type thermocouple (Omega

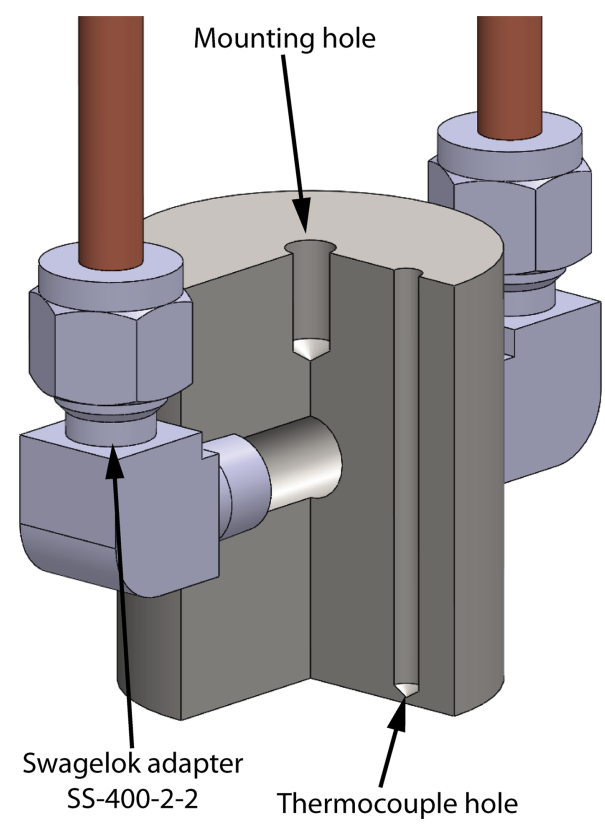

FIG. 2. Rendering of the flame stabilization plate. A transparent view of the plate is shown with fittings for cooling water attached to the sides. The circular plate has the same diameter as the inner sintered bronze plug of the burner (38.1 mm) and is mounted $13.6 \mathrm{~mm}$ above the burner surface. The cooling water is maintained at a temperature of $15^{\circ} \mathrm{C}$ in order to keep the plate at a temperature of approximately $100^{\circ} \mathrm{C}$, which yields stable flames and mitigates water condensation on the plate.

Engineering, Inc. model KMQXL-125U-6) positioned inside the plate, $0.64 \mathrm{~mm}$ from its underside (i.e., from the top of the flame), and is regulated using cooled water. The temperature $\left(15^{\circ} \mathrm{C}\right)$ and flow rate $(0.57 \mathrm{l} / \mathrm{min})$ of this water have been chosen to maintain a stabilization plate temperature close to 100 ${ }^{\circ} \mathrm{C}$, which yields stable flames and prevents condensation of water from the burner exhaust. When operating under fuel-rich conditions, soot collects on the underside of the plate, resulting in a decrease of the temperature recorded by the thermocouple by about $1 \%-2 \% / \mathrm{hr}$.

A rendering of the combined burner-plate assembly is provided in Fig. 3. The choice of hardware to mount the plate over the burner mouth is arbitrary but should be sufficiently rigid to prevent warping induced by the component weights or forces imposed by the gas/water lines. Thermal expansion of the aluminum structure on which the stabilizer plate is mounted is estimated to be negligible.

\section{B. External plumbing}

A schematic diagram of the gas- and water-handling systems for this burner is provided in Fig. 4. Ultra-high-purity (UHP) gases are regulated to a pressure of $35 \mathrm{psi}$ (gauge) $(\sim 240 \mathrm{kPa})$, directed through $0.5-\mu \mathrm{m}$ filters (Swagelok model SS-4F-05), and their flow rates are controlled by mass-flow controllers (MKS Instruments, Inc. model GM50A, calibrated to an accuracy of better than $\pm 3 \%$ at full scale relative to $0{ }^{\circ} \mathrm{C}$ and $1 \mathrm{~atm}$ using a Sierra Instruments, Inc. model SL-500 calibration instrument). The shroud gas is then sent to the burner, whereas the gases comprising the combustible mixture are first fed through a mixing tube (McMaster-Carr Supply 


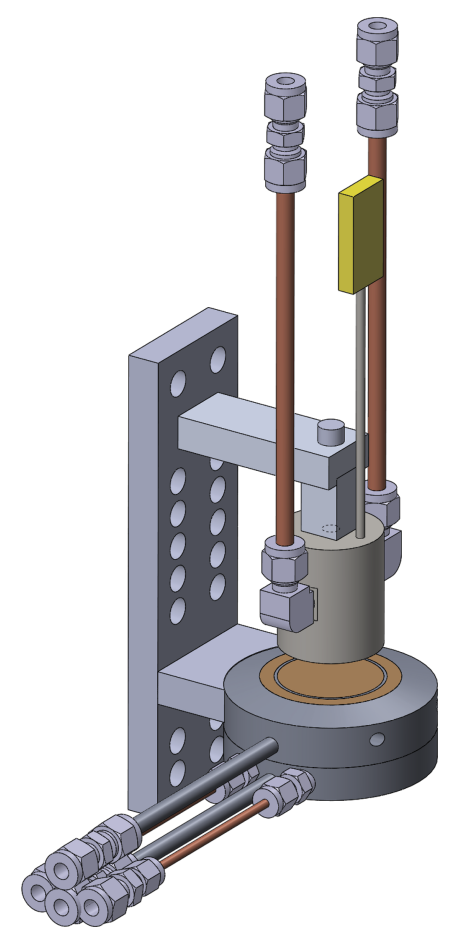

FIG. 3. Rendering of the miniature McKenna burner with stabilization plate and mounting brackets. The stabilization plate is held $13.6 \mathrm{~mm}$ above the burner surface, centered over the inner sintered bronze plug. This configuration allows easy access for both in situ and ex situ diagnostics.

Co. model 3529K51) followed by a flashback arrestor (WITTGasetechnik GmbH \& Co. KG model F53N/H). The flashback arrestor ensures that a flashback cannot reach the mixing tube in the event of a failure that compromises the integrity of the porous plug. The mixing tube is necessary to ensure adequate blending of the reactive gases prior to entering the burner because the burner's internal volume is too small to guarantee complete mixing. We use a flashback arrestor that does not have a return check valve because the model with this valve $(\mathrm{RF} 53 \mathrm{~N} / \mathrm{H})$ vibrates and disrupts the flame. For safety reasons, the distance between the final flashback arrestor and the burner is as short as possible in order to minimize the volume of the flammable mixture exposed to the flame front.

Because of the propensity for rich premixed hydrocarbon flames to produce excessive amounts of carbon monoxide and other combustion byproducts, the burner assembly is contained in a clear acrylic flame enclosure with an exhaust duct mounted on the top, as in previous configurations. ${ }^{29,30}$ This flame enclosure serves to both contain exhaust gases and soot and to provide a barrier for the prevention of flame flickering due to laboratory-air currents. Carbon monoxide levels just outside this enclosure are monitored using a probe (RKI Instruments, Inc. model GD-70D) positioned on top of this flame enclosure.

The distilled cooling water supplied to the burner is maintained at $15^{\circ} \mathrm{C}$ by a chiller (NESLAB Instruments, Inc. model RTE-111) and flows at a rate of $\sim 0.22 \mathrm{l} / \mathrm{min}$. A similar chiller supplies water, also at $15^{\circ} \mathrm{C}$, to the stabilization plate at a rate of $0.57 \mathrm{l} / \mathrm{min}$. The temperature increase in the water returning

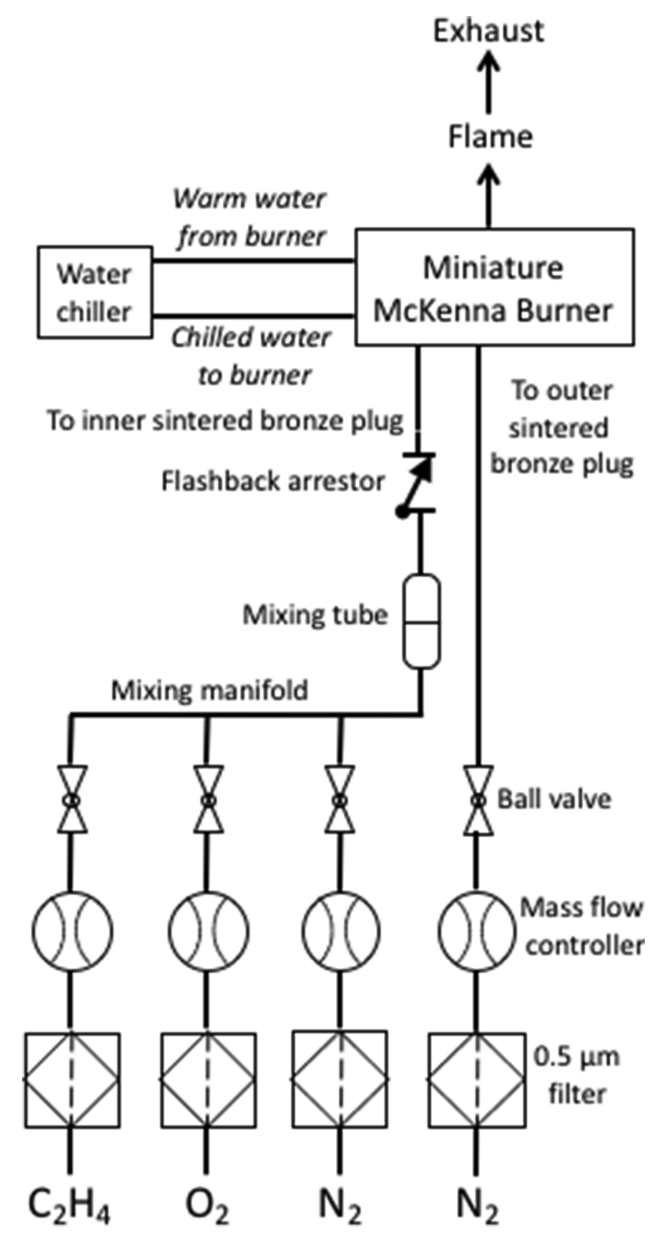

FIG. 4. Plumbing diagram for the miniature McKenna burner. Gases comprising the flammable mixture pass through filters, mass-flow controllers, and shut-off valves, are combined in a mixing manifold, are blended in a mixing tube, pass through a flashback arrestor, and travel to the inner sintered bronze plug. The shroud gas travels directly to the outer sintered bronze plug following the filter, mass-flow controller, and shut-off valve.

from the burner is typically less than $3{ }^{\circ} \mathrm{C}$, and the temperature of the underside of the burner is normally $25^{\circ} \mathrm{C}$.

\section{GAS-MIXTURE DESIGN}

One advantage of premixed flames is that they allow precise mixture design, which enables comparisons between the combustion of different fuels and gas-dilution mixtures to be performed systematically. Several mixture variables can be controlled for a generic mixture that contains molecular oxygen $\left(\mathrm{O}_{2}\right)$ with mole fraction $x_{\mathrm{O}_{2}}$, a diluent (often $\mathrm{Ar}$ or $\mathrm{N}_{2}$, but sometimes $\mathrm{CO}_{2}$ ) with mole fraction $x_{D}$, and some number of fuels $N_{f}$ with mole fractions $x_{i}\left(1 \leq i \leq N_{f}\right.$, with each fuel possessing $n_{\mathrm{C}, i}$ carbon atoms, $n_{\mathrm{H}, i}$ hydrogen atoms, and $n_{\mathrm{O}, i}$ oxygen atoms per molecule). We present results in this paper for a single fuel, but the equations given below can be used to generate mixtures of multiple fuels if desired.

The equivalence ratio $\phi$ can be written as

$$
\phi=\frac{\sum_{1}^{N_{f}} x_{i}\left(n_{\mathrm{C}, i}+\frac{1}{4} n_{\mathrm{H}, i}-\frac{1}{2} n_{\mathrm{O}, i}\right)}{x_{\mathrm{O}_{2}}},
$$


TABLE II. Gas-flow rates for several flames stabilized on the miniature McKenna burner. ${ }^{\mathrm{a}}$

\begin{tabular}{lccccccc}
\hline \hline Flame & $\begin{array}{c}\text { Ethylene } \\
\mathrm{C}_{2} \mathrm{H}_{4}(\mathrm{SCCM})\end{array}$ & $\begin{array}{c}\text { Oxygen } \mathrm{O}_{2} \\
(\mathrm{SCCM})\end{array}$ & $\begin{array}{c}\text { Nitrogen } \\
\mathrm{N}_{2}(\mathrm{SCCM})\end{array}$ & $\begin{array}{c}\text { Nitrogen shroud } \\
\mathrm{N}_{2}(\mathrm{SCCM})\end{array}$ & $\begin{array}{c}\mathrm{N}_{2}: \mathrm{O}_{2} \\
\text { ratio } R_{D O}\end{array}$ & $\begin{array}{c}\text { C:O ratio } \\
R_{\mathrm{CO}}\end{array}$ & $\begin{array}{c}\text { Equivalence } \\
\text { ratio } \phi\end{array}$ \\
\hline ME1 & 673 & 961 & 3616 & 19000 & 3.76 & 0.70 & 2.10 \\
ME2 & 587 & 979 & 3683 & 19000 & 3.76 & 0.60 & 1.80 \\
ME3 & 499 & 998 & 3753 & 19000 & 3.76 & 0.50 & 1.50 \\
\hline \hline
\end{tabular}

${ }^{\mathrm{a} S C C M}$ denotes standard $\left(0{ }^{\circ} \mathrm{C}, 1 \mathrm{~atm}\right)$ cubic centimeters per minute, and $\phi$ denotes equivalence ratio.

and the $\mathrm{C}: \mathrm{O}$ ratio $\left(R_{\mathrm{CO}}\right)$ can be written as

$$
R_{\mathrm{CO}}=\frac{\sum_{1}^{N_{f}} x_{i} n_{\mathrm{C}, i}}{2 x_{\mathrm{O}_{2}}+\sum_{1}^{N_{f}} x_{i} n_{\mathrm{O}, i}} .
$$

Additionally, the molar ratio of diluent to molecular oxygen is

$$
R_{D \mathrm{O}}=\frac{x_{D}}{x_{\mathrm{O}_{2}}},
$$

and the molar ratio of fuel $i$ to fuel 1 is

$$
R_{i 1}=\frac{x_{i}}{x_{1}}
$$

where $R_{11}=1$ for fuel number 1 . The sum of the mole fractions of all of the components is unity,

$$
x_{\mathrm{O}_{2}}+x_{D}+\sum_{1}^{N_{f}} x_{i}=1 .
$$

These equations can be rearranged to produce relationships specifying the mole fractions of individual mixture components. To design a mixture with specified values of $\phi, R_{D \mathrm{O}}$, and $R_{i 1}$, the mole fractions of individual components are

$$
\begin{gathered}
x_{1}=\left\{\sum_{1}^{N_{f}} R_{i 1}+\frac{1}{\phi}\left(1+R_{D \mathrm{O}}\right)\right. \\
\left.\times \sum_{1}^{N_{f}} R_{i 1}\left(n_{\mathrm{C}, i}+\frac{1}{4} n_{\mathrm{H}, i}-\frac{1}{2} n_{\mathrm{O}, i}\right)\right\}^{-1}, \\
x_{i}=R_{i 1} x_{1}, \\
x_{\mathrm{O}_{2}}=\frac{1-x_{1} \sum_{1}^{N_{f}} R_{i 1}}{1+R_{D \mathrm{O}}}, \\
x_{D}=R_{D \mathrm{O}} x_{\mathrm{O}_{2}} .
\end{gathered}
$$

In mixtures that specify $R_{\mathrm{CO}}, R_{D \mathrm{O}}$, and $R_{i 1}$, the mole fraction of hydrocarbon 1 is

$$
\begin{aligned}
x_{1}= & \left\{\sum_{1}^{N_{f}} R_{i 1}+\frac{1}{2}\left(1+R_{D \mathrm{O}}\right)\left[\frac{1}{R_{\mathrm{CO}}} \sum_{1}^{N_{f}} R_{i 1} n_{\mathrm{C}, i}\right.\right. \\
& \left.\left.-\sum_{1}^{N_{f}} R_{i 1} n_{\mathrm{O}, i}\right]\right\}^{-1},
\end{aligned}
$$

and the other mole fractions can be obtained using Eqs. (7)-(9). We have provided derivations for these equations in Sec. S1 of the supplementary material and have confirmed that these relationships reproduce mixtures reported in the literature (e.g., from Refs. 28,32,43-51). The volumetric flow rates of individual components may be obtained from the component mole fractions by multiplying these values by the desired total mixture volumetric flow rate.

Using these equations, we designed several mixtures of ethylene and engineered air $\left(79 \% \mathrm{~N}_{2}, 21 \% \mathrm{O}_{2}\right.$ on a molar basis, giving the molar ratio of diluent to $\mathrm{O}_{2}, R_{D \mathrm{O}}=0.79 / 0.21 \approx 3.76$ ), reported in Table II. Henceforth, flames will be referred to by the descriptors used in these tables (e.g., ME1, ME2, or ME3). Flames ME1, ME2, and ME3 are ethylene/air flames that show a reduction in $\phi$ and $R_{\mathrm{CO}}$ while keeping $R_{D \mathrm{O}}$ constant.

All flames listed in Table II are operated under ambient conditions (i.e., at atmospheric pressure). The velocity of the shroud flow exceeds that of the premixed gases in order to provide enhanced stability for the flame; this strategy has been employed by others as well. ${ }^{29,30}$

\section{FLAME CHARACTERIZATION}

\section{A. Flame description}

Photographs of three ethylene/air flames are provided in Fig. 5; they were obtained using a Canon EOS 5D digital camera with a Canon EF 24-85 mm zoom lens. In flame ME1 [Fig. 5(a)], two distinct luminous zones are visible for this rich $(\phi=2.1)$, sooting $\left(R_{\mathrm{CO}}=0.7\right)$ flame, including a blue/green region caused primarily by $\mathrm{CH}$ and $\mathrm{C}_{2}$ radical emission centered $\sim 1.5 \mathrm{~mm}$ above the burner surface and an orange/yellow region where soot luminesces. All of the molecular oxygen $\left(\mathrm{O}_{2}\right)$ is consumed within the first few millimeters of the flame, ${ }^{52}$ yielding a mixture of hydrocarbons with a low $\mathrm{C} / \mathrm{H}$ ratio, which continues to pyrolyze. This type of flame has been used extensively for studying soot inception and growth. ${ }^{53-63}$ Flame ME2 [Fig. 5(b)] is very weakly

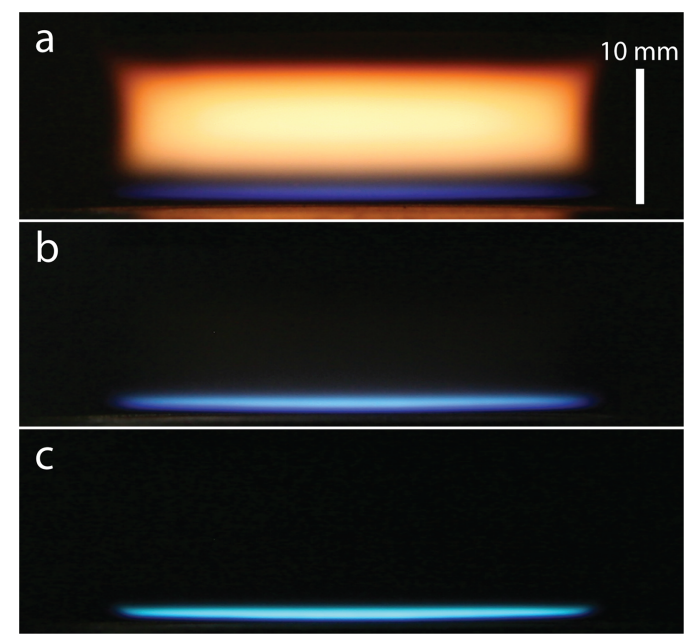

FIG. 5. Photographs of premixed ethylene/air flat flames. Images show flames that correspond to the flow rates given in Table II for (a) flame ME1 $(\phi=2.1)$, (b) flame ME2 ( $\phi=1.8)$, and (c) flame ME3 $(\phi=1.5)$. Photographs for flames ME1 and ME3 were taken using the same zoom $(85 \mathrm{~mm})$, aperture setting (f/13), and exposure $(0.5 \mathrm{~s})$; the exposure for flame ME2 was $1 \mathrm{~s}$. 
sooting (the soot-radiation zone is too weak to be seen in the photograph), and flame ME3 [Fig. 5(c)] produces no visible soot.

\section{B. Temperature profiles}

We measured vertical profiles of temperatures for flames ME1, ME2, and ME3 along the centerline using direct one-dimensional CARS, details of which are available elsewhere. $^{52,64,65}$ The results are displayed as a function of HAB in Fig. 6 and are tabulated in Table S1 of the supplementary material. This figure demonstrates that the increase in equivalence ratio results in a delayed temperature increase, which, as noted by Prucker et al. ${ }^{28}$ can be explained by the decreasing flame speed of the mixture that results in an increasing reaction zone standoff distance. Except for gradients in temperature near the burner and stabilization plates, temperatures are relatively constant throughout the central region of the flames. The maximum temperature of flame ME1 agrees well with that measured in a conventional McKenna burner by Bladh et al. ${ }^{52,57}$

\section{Flame simulations}

The steady, laminar, premixed environment provided by stabilized McKenna burners allows simulations of flame chemistry. Figure 6 shows comparisons of the measured temperature profiles with profiles calculated using CHEMKIN-PRO ${ }^{66,67}$ with the USC-Mech II reaction mechanism. ${ }^{68}$ These calculations do not account for heat transfer losses due to radiation, which is expected to produce small errors in the results. ${ }^{22}$ The best agreement between the modeled and measured profiles is demonstrated for the leanest flame; the agreement between modeled and measured profiles is significantly worse for the richest flame (ME1) than for the other two flames. This result is understandable, given that the model only accounts for formation of smaller hydrocarbons and fails to predict larger hydrocarbons and soot formation, making it less accurate for

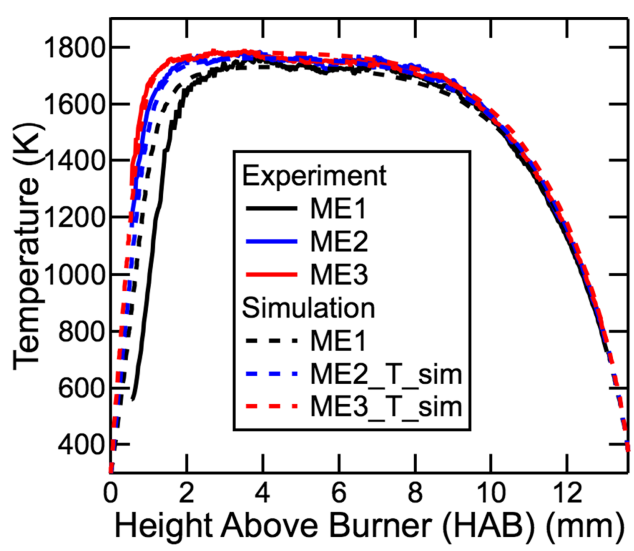

FIG. 6. Temperature profiles for several premixed ethylene/air flat flames. Temperature measurements were made using CARS along the centerline as a function of HAB and are shown for flames ME1 $(\phi=2.1), \operatorname{ME2}(\phi=1.8)$, and ME3 $(\phi=1.5)$ described in Table II and shown in Fig. 5. Values are provided in Table S1 of the supplementary material. Modeled temperature profiles were calculated using CHEMKIN-PRO ${ }^{66,67}$ with the USC-Mech II reaction mechanism. ${ }^{68}$ The temperature measurements are described by Bohlin and Kliewer. $^{52}$ rich sooting flames than for leaner flames. Nevertheless, the simulations predict the trend of increasing reaction zone lift-off height with equivalence ratio, as has been demonstrated previously; ${ }^{28,69}$ the simulations also yield good agreement with measured maximum flame temperatures.

Figure 7 shows calculated temperature and major species mole-fraction profiles for stabilization-plate distances of $13.6 \mathrm{~mm}$ (for the miniature McKenna burner) and $21 \mathrm{~mm}$ (for conventional McKenna burners). The maximum temperature is almost identical for the two plate distances $(1730 \mathrm{~K}$ for $13.6 \mathrm{~mm}$ and $1736 \mathrm{~K}$ for $21 \mathrm{~mm}$ ), but the temperature plateau with $\mathrm{HAB}$ extends to higher HAB for the $21-\mathrm{mm}$ distance, as expected. The mole-fraction profiles of the major species, except water and hydrogen, are very similar throughout the entire shared 13.6-mm distance; the profiles for water and hydrogen agree below about $2 \mathrm{~mm}$. A rate-of-production (ROP) analysis revealed that the difference in the $\mathrm{H}_{2} \mathrm{O}$ and $\mathrm{H}_{2}$ profiles is attributable to the reaction $\mathrm{OH}+\mathrm{H}_{2} \leftrightarrow \mathrm{H}+$ $\mathrm{H}_{2} \mathrm{O}$. The reverse (endothermic, hydrogen production) direction of this reaction proceeds rapidly at high temperatures, whereas the forward (exothermic, water production) direction is favored at low temperatures. At intermediate burner heights, the above reaction thus favors hydrogen production, as evidenced by the increasing hydrogen and decreasing water mole fractions. However, as the temperature drops in the 13.6-mm flame, the reaction slows and then actually proceeds in the forward direction (water production), until all reactions are quenched as the stabilization plate temperature is reached. This temperature drop is delayed in the 21-mm flame, allowing

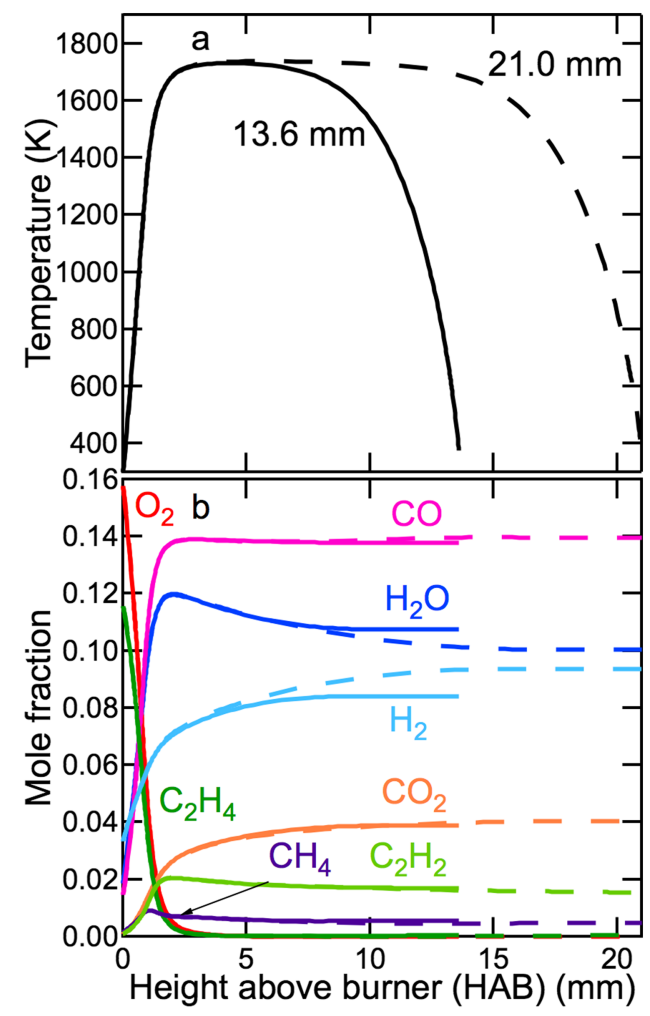

FIG. 7. Calculated (a) temperature and (b) mole-fraction profiles for a stabilization plate distance of $13.6 \mathrm{~mm}$ (solid lines) and $21.0 \mathrm{~mm}$ (dashes). Calculations were performed using CHEMKIN-PRO ${ }^{66,67}$ with the USC-Mech II reaction mechanism ${ }^{68}$ in flame ME1. Nitrogen is present but not shown. 
for increased production of molecular hydrogen. Calculated mole-fraction profiles for important reactants, intermediates, and product species are discussed in Sec. S2 and are shown in Fig. S1 of the supplementary material.

\section{Species distributions}

We extracted particles and condensed precursors from the flame for analysis using a VUV-AMS. These measurements were performed at the Chemical Dynamics Beamline at the Advanced Light Source (ALS) at Lawrence Berkeley National Laboratory in Berkeley, CA, USA; details are available elsewhere, ${ }^{61,62,70-72}$ and only a brief description of this technique will be provided here. We extracted soot from the flame using a quartz probe, and particles were focused using an aerodynamic lens system. ${ }^{73,74}$ The particle beam impinged on a heated copper target $(\sim 570 \mathrm{~K})$ located in the ionization chamber of the VUV-AMS (operating pressure of $7 \times 10^{-7}$ Torr). Species that were thermally vaporized from the heated target were photoionized using synchrotron-generated vacuum ultraviolet (VUV) single-photon ionization. The ions generated were pulse-extracted into the drift tube of a time-of-flight mass spectrometer.

Figure 8 shows an aerosol mass spectrum recorded from soot extracted at an HAB of $3.4 \mathrm{~mm}$ from flame ME1. ${ }^{62}$ The mass peaks are organized in clusters where each cluster generally corresponds to a specific number of carbon atoms, and the different peaks in each cluster generally correspond to different levels of saturation, i.e., hydrogen content.

A plot of the estimated number of hydrogen atoms as a function of the number of carbon atoms at each mass peak (Fig. 9) demonstrates that the spread in hydrogen content is substantial both low and high in ME1. Peaks tend to be stronger for nominal masses corresponding to even numbers of carbon and hydrogen atoms. Extractive sampling, however, may preferentially lead to suppression of radicals. ${ }^{75}$ Furthermore, strong peaks generally correspond to species of relatively low saturation, suggesting that the aromatic content is substantial. A majority of these strong peaks have molecular formulas consistent with those of the most stable hydrocarbon structures known as "stabilomers."76 Nevertheless, recent studies on

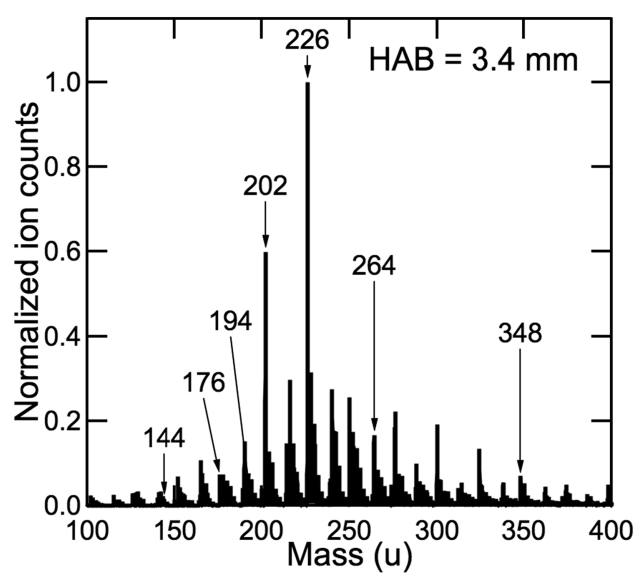

FIG. 8. Aerosol mass spectrum of particles extracted from flame ME1 at an $\mathrm{HAB}$ of $3.4 \mathrm{~mm}$. This graphic is a modification of a figure from the work of Johansson et al. ${ }^{62}$

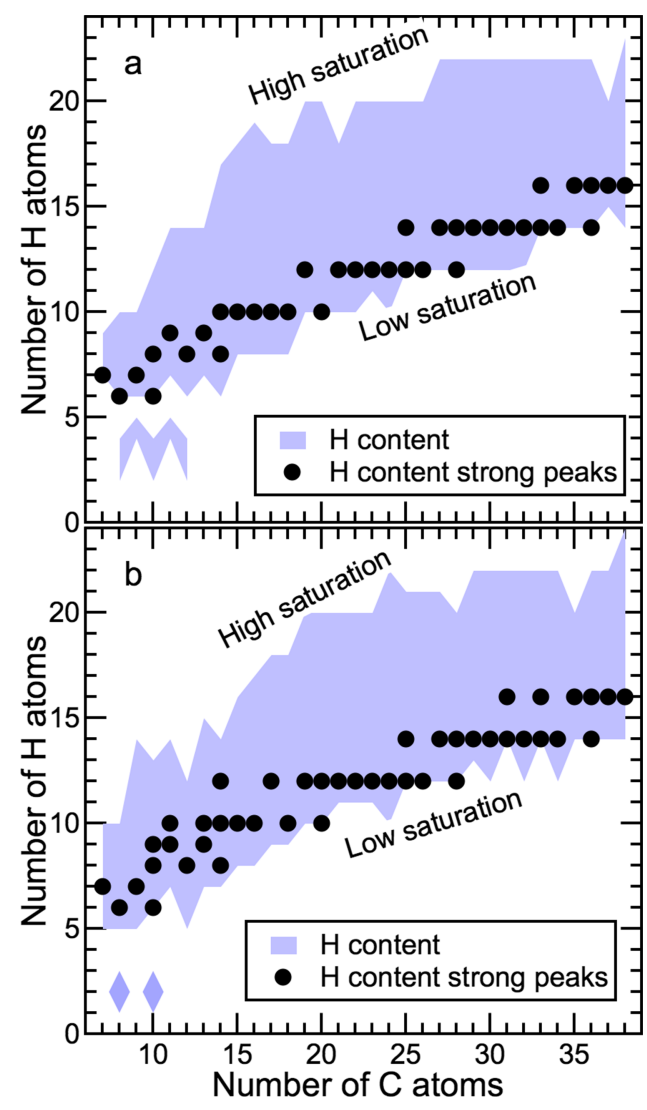

FIG. 9. Estimated number of $\mathrm{H}$ atoms vs $\mathrm{C}$ atoms at each mass peak. The shaded region demonstrates the spread in hydrogen content corresponding to the number of carbons in the species. The black dots represent the masses of particularly intense peaks in each cluster. Results are shown for an HAB of (a) $7.4 \mathrm{~mm}$ and (b) $3.4 \mathrm{~mm}$.

flame ME1 showed that the stabilomers pyrene and coronene alone could not account for the signals observed at $202 \mathrm{u}$ $\left(\mathrm{C}_{16} \mathrm{H}_{10}\right)$ and $300 \mathrm{u}\left(\mathrm{C}_{24} \mathrm{H}_{12}\right){ }^{62,72}$ In addition, the stabilomer grid does not account for species containing odd numbers of carbon atoms. ${ }^{76}$

Figure 9 also shows that the mass spectra contain signals from the large polyynes $\mathrm{C}_{8} \mathrm{H}_{2}, \mathrm{C}_{10} \mathrm{H}_{2}$, and $\mathrm{C}_{12} \mathrm{H}_{2}$. These species have nearly the same masses as $\mathrm{C}_{7} \mathrm{H}_{14}, \mathrm{C}_{9} \mathrm{H}_{14}$, and $\mathrm{C}_{11} \mathrm{H}_{14}$. Nevertheless, the precise masses of the peaks at nominal masses 98, 122, and $146 \mathrm{u}$ are in closer agreement with the masses of the three polyynes than with the masses of the more H-rich species. In addition, it seems likely that if the three peaks at 98, 122, and $146 \mathrm{u}$ had stemmed from the $\mathrm{H}$-rich $\mathrm{C}_{7} \mathrm{H}_{14}, \mathrm{C}_{9} \mathrm{H}_{14}$, and $\mathrm{C}_{11} \mathrm{H}_{14}$ species, the mass spectra would have contained more pronounced peaks at nearby masses corresponding to less saturated species, for example, $\mathrm{C}_{7} \mathrm{H}_{12}(96 \mathrm{u}), \mathrm{C}_{9} \mathrm{H}_{12}(120 \mathrm{u})$, and $\mathrm{C}_{11} \mathrm{H}_{12}(144 \mathrm{u})$. Instead, the peaks at 98, 122, and, to a lesser extent, $146 \mathrm{u}$, are significantly stronger than nearby peaks at lower masses, which make them relatively isolated. Polyynes may appear as isolated peaks in between clusters because of their very low saturation. ${ }^{61}$

The photoionization thresholds of mass peaks 98 and $122 \mathrm{u}$ also suggest that they stem from polyynes; the photoionization thresholds of these two peaks agree with the values provided for $\mathrm{C}_{8} \mathrm{H}_{2}$ and $\mathrm{C}_{10} \mathrm{H}_{2}$ by Hansen et al. ${ }^{77}$ The signal 
of the peak at $146 \mathrm{u}$, however, is too weak to allow accurate determination of its photoionization threshold.

Figures 8 and 9 suggest that flame ME1 contains a significantly broader distribution of species than can be explained by the stabilomer grid. Both pure hydrocarbon species and partially oxidized species are among the species generated. ${ }^{61}$ These conclusions are supported by earlier studies performed in ME1 and in acetylene and ethylene counter-flow diffusion flames. ${ }^{62,71,72}$

\section{E. Soot-volume fractions}

We used laser-induced incandescence (LII) to measure soot-volume fractions in flame ME1. These measurements also provide information about the stability of the burner over time and the uniformity of the soot distribution across the burner surface. Details of the laser setup are given elsewhere; ${ }^{78-80}$ we will only provide the most relevant information here. Soot particles in the flame were irradiated using the fundamental $(1064 \mathrm{~nm})$ output from a pulsed (10-ns duration; $10 \mathrm{~Hz})$ injection-seeded Nd:YAG laser. The beam passed through a $2 \times 2 \mathrm{~mm}^{2}$ square ceramic aperture, which selected the most spatially and temporally homogeneous region of the beam. ${ }^{78}$ The beam profile at the aperture was relay-imaged to the flame using a 2:1 reducing telescope, which resulted in a beam size of approximately $1 \times 1 \mathrm{~mm}^{2}$ at the measurement location with a temporal spread of less than 550 ps across the beam in either direction and an intensity spread of $\pm 12.4 \%$ across the beam profile. We used a fluence of $1 \mathrm{~J} / \mathrm{cm}^{2}$ to ensure that soot sublimation temperatures were reached and that peakLII signal values were independent of any small laser fluence changes. ${ }^{24}$ We used a 1:1 achromatic telescope to image the LII signal onto a gated photomultiplier tube (PMT) with a rise time of $780 \mathrm{ps}$. The telescope and PMT were mounted perpendicular to the incident beam. The gated PMT was used to reduce the detector saturation by reducing the detector current associated with continuous background flame luminosity hitting the detector. The signal passed through a bandpass filter $(681.8 \pm 10 \mathrm{~nm})$ and a $700-\mu \mathrm{m}$ circular aperture in front of the PMT. We temporally resolved the LII signal and converted the maxima of the LII temporal profiles (i.e., peak-LII signals) to soot-volume fraction using a calibration based on extinction measurements performed on a linear diffusion flame described in more detail by Campbell et al. ${ }^{81}$ Briefly, we used LII measured at two laser wavelengths to infer a dispersion exponent $(\xi)$ and absorption scaling factor $(\beta)$, as described by López-Yglesias et al..$^{82}$ and Johansson et al. ${ }^{83}$ We used these values of $\xi$ and $\beta$ to derive values of the refractiveindex function for absorption $E(m)$ as a function of HAB for the diffusion flame. We used ratios of the refractiveindex function for scattering $F(m)$ relative to $E(m)$ derived by Michelsen et al. ${ }^{79}$ to infer values of $F(m)$ at 532 and $1064 \mathrm{~nm}$ and then used the resulting values of $F(m)$ and $E(m)$ to derive an extinction coefficient $\mathrm{K}_{e}$ as a function of $\mathrm{HAB}$ for 532 and $1064 \mathrm{~nm} .{ }^{81}$ The resulting values of $K_{e}$ agreed well (to within $15 \%$ ) with those reported previously by Williams et al. ${ }^{84}$ We measured the transmittance as a function of HAB for 532 and $1064 \mathrm{~nm}$ to derive a soot-volume fraction, which was then used to calibrate the peak-LII signal for the same optical

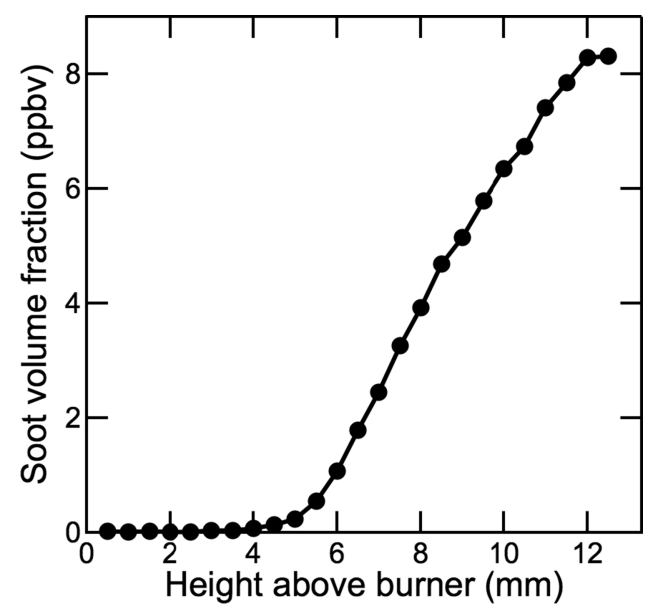

FIG. 10. Vertical profile of soot-volume fractions in a premixed ethylene/air flame. Measurements were made on the vertical centerline of flame ME1 using LII with a laser wavelength of $1064 \mathrm{~nm}$ and a fluence of $1 \mathrm{~J} / \mathrm{cm}^{2}$. Values are given in Table S3 of the supplementary material.

setup used for the premixed flame described in the present study. ${ }^{81}$

Figure 10 provides a soot-volume-fraction profile measured vertically in the center of the burner in flame ME1. The volume-fraction values reported here are 2-15 times smaller than those measured previously in similar premixed ethylene/air flames. ${ }^{21,23,32,85}$ This reduction is likely predominantly attributable to the smaller stabilization plate standoff distance of the miniature McKenna burner, which limits the time available for soot formation and graphitization to occur. The soot-volume fraction increases with HAB. The volumefraction measurements reported here are tabulated in Table S3 of the supplementary material.

Figure 11 shows soot-volume fractions at HABs of $6 \mathrm{~mm}$ and $10 \mathrm{~mm}$ in flame ME1, measured as a function of radial position (achieved by translating the burner horizontally along the beam path). The radial profiles at both HABs are

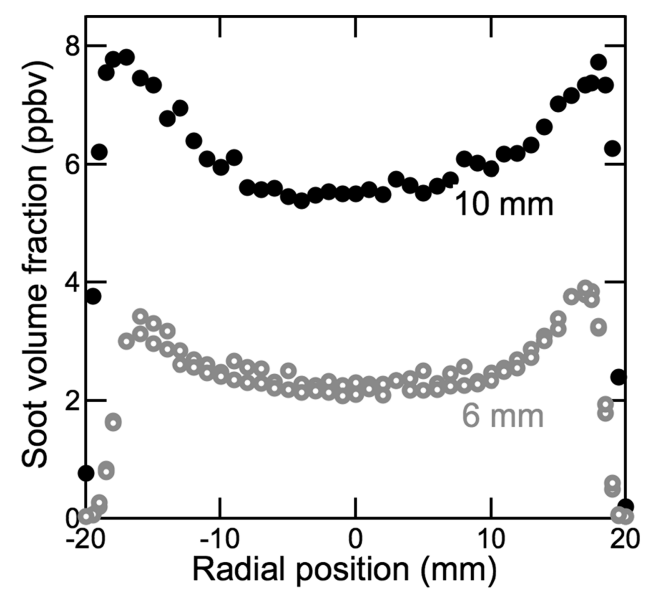

FIG. 11. Horizontal profiles of soot-volume fraction in a premixed ethylene/air flame. LII measurements were made at HABs of $6 \mathrm{~mm}$ and $10 \mathrm{~mm}$ in flame ME1 by translating the burner horizontally. The laser wavelength was $1064 \mathrm{~nm}$, and the fluence was $1 \mathrm{~J} / \mathrm{cm}^{2}$. Values are given in Table S3 of the supplementary material. 
homogeneous in the central region to a radius of about $10 \mathrm{~mm}$ and exhibit higher soot-volume fractions near the edges of the flame. These radial profiles are more homogeneous that those measured previously in conventional McKenna burners. ${ }^{23,32}$ Our results also demonstrate slightly increased soot-volume fractions at the edge, in contrast to the decreased soot-volume fractions measured at the edge with a nitrogen co-flow in a conventional McKenna burner. ${ }^{23,32}$

Previous work using a standard McKenna burner has demonstrated a transient effect in the LII signal as the burner heats up. ${ }^{23,85}$ Although this effect was not obvious in our measurements, we found a strong sensitivity of our signal to the temperatures of our flow controllers. As a result, the LII signal decreased significantly as the room temperature in creased. Stabilizing the temperature of the flow controllers and their electronics eliminated the variability of the signal with time.

\section{SUMMARY}

In this paper, we have detailed the design, construction, and operation of a small porous-plug burner based on the design of a McKenna burner for use in space-constrained applications and for leveraging a database for this burner for which some of the available measurements were spatially constrained. We have provided characterization data for ethylene/air flames produced by this burner, including temperature profiles, model species profiles, VUV-AMS particle-species profiles, and soot-volume fractions. We have also discussed differences between this miniature burner and its larger counterparts. Flame temperatures were similar to those found in full-size McKenna burners. Inferred soot-volume fractions, however, seem to be lower than those in full-size burners. Flame simulations performed using CHEMKIN-PRO predicted temperatures that agreed well with measured temperatures and provide useful complementary information about the gas-phase species produced at different heights in the flame.

\section{SUPPLEMENTARY MATERIAL}

See supplementary material for derivations of Eqs. (1), (2), (6), and (10), which are given in the supplementary text file. Tabulated temperature profiles recorded using CARS measurements for flames ME1, ME2, and ME3, as shown in Fig. 6, are given in Table S1. Calculated species profiles using CHEMKIN-PRO are shown for a selection of gas-phase species in Fig. S1. Soot-volume-fraction measurements shown in Figs. 10 and 11 are tabulated in Table S2. CAD (mechanical) drawings are in a file named MiniMcKennaDrawings.pdf.

\section{ACKNOWLEDGMENTS}

We thank Dr. Kevin Wilson for the use of his aerosol mass spectrometer at the Advanced Light Source (ALS). This work was supported by the Division of Chemical Sciences, Geosciences, and Biosciences, the Office of Basic Energy Sciences (BES), the U.S. Department of Energy (DOE). K.O.J. was funded by DOE BES under the Single Investigator Small
Group Research (SISGR), Grant No. DE-SC0002619. A.L.S. and N.K.R.H. were supported by the Director, DOE BES, under Contract No. DE-AC02-05CH11231. Sandia National Laboratories is a multi-mission laboratory managed and operated by National Technology and Engineering Solutions of Sandia, LLC., a wholly owned subsidiary of Honeywell International, Inc., for the U.S. Department of Energy's National Nuclear Security Administration under Contract No. DENA0003525.

${ }^{1}$ J. S. Lighty, J. M. Veranth, and A. F. Sarofim, J. Air Waste Manage. Assoc. 50(9), 1565 (2000).

${ }^{2}$ E. J. Highwood and R. P. Kinnersley, Environ. Int. 32, 560 (2006).

${ }^{3}$ T. C. Bond, S. J. Doherty, D. W. Fahey, P. M. Forster, T. Berntsen, B. J. DeAngelo, M. G. Flanner, S. Ghan, B. Kärcher, D. Koch, S. Kinne, Y. Kondo, P. K. Quinn, M. C. Sarofim, M. G. Schultz, M. Schulz, C. Venkataraman, H. Zhang, S. Zhang, N. Bellouin, S. K. Guttikunda, P. K. Hopke, M. Z. Jacobson, J. W. Kaiser, Z. Klimont, U. Lohmann, J. P. Schwarz, D. Shindell, T. Storelvmo, S. G. Warren, and C. S. Zender, J. Geophys. Res.: Atmos. 118(11), 5380, doi:10.1002/jgrd.50171 (2013).

${ }^{4}$ H. Richter and J. B. Howard, Prog. Energy Combust. Sci. 26, 565 (2000).

${ }^{5}$ M. Frenklach, Phys. Chem. Chem. Phys. 4(11), 2028 (2002).

${ }^{6}$ H. Wang, Proc. Combust. Inst. 33, 41 (2011).

${ }^{7}$ H. A. Michelsen, Proc. Combust. Inst. 36(1), 717 (2017).

${ }^{8}$ J. Boulanger, F. Liu, W. S. Neill, and G. J. Smallwood, J. Eng. Gas Turbines Power 129(3), 877 (2007).

${ }^{9}$ J. Boulanger, W. S. Neill, F. Liu, and G. J. Smallwood, J. Eng. Gas Turbines Power 130(6), 062808 (2008).

${ }^{10}$ J. O'Conner and M. Musculus, SAE Int. J. Aerosp. 6(1), 400 (2013).

${ }^{11}$ J. Powling, Fuel 28(2), 25 (1949).

${ }^{12}$ A. Egerton and S. K. Thabet, Proc. R. Soc. A 211(1107), 445 (1952).

${ }^{13}$ R. E. Donovan and W. G. Agnew, J. Chem. Phys. 23(9), 1592 (1955).

${ }^{14}$ W. G. Agnew, J. T. Agnew, and K. Wark, Symp. (Int.) Combust. 5(1), 766 (1955).

${ }^{15}$ W. G. Agnew and J. T. Agnew, Ind. Eng. Chem. 48(12), 2224 (1956).

${ }^{16}$ J. P. Botha and D. B. Spalding, Proc. R. Soc. A 225(1160), 71 (1954).

${ }^{17}$ W. E. Kaskan, Symp. (Int.) Combust. 6(1), 134 (1957).

${ }^{18}$ W. E. Kaskan, Combust. Flame 2(3), 229 (1958).

${ }^{19}$ G. Kroner, H. Fuchs, R. Tatschl, and O. Glatter, Part. Part. Syst. Charact. 20(2), 111 (2003).

${ }^{20}$ D. W. Senser, J. S. Morse, and V. A. Cundy, Rev. Sci. Instrum. 56(6), 1279 (1985).

${ }^{21}$ R. Hadef, K. P. Geigle, W. Meier, and M. Aigner, Int. J. Therm. Sci. 49(8), 1457 (2010).

${ }^{22}$ M. A. Gregor and A. Dreizler, Meas. Sci. Technol. 20(6), 065402 (2009).

${ }^{23}$ N. E. Olofsson, H. Bladh, A. Bohlin, J. Johnsson, and P. E. Bengtsson, Combust. Sci. Technol. 185(2), 293 (2013).

${ }^{24}$ H. A. Michelsen, C. Schulz, G. J. Smallwood, and S. Will, Prog. Energy Combust. Sci. 51, 2 (2015).

${ }^{25}$ N. G. Glumac and D. G. Goodwin, Thin Solid Films 212(1-2), 122 (1992).

${ }^{26}$ A. Van Maaren, D. S. Thung, and L. R. H. De Goey, Combust. Sci. Technol. 96(4-6), 327 (1994).

${ }^{27}$ G. Hartung, J. Hult, and C. F. Kaminski, Meas. Sci. Technol. 17(9), 2485 (2006).

${ }^{28}$ S. Prucker, W. Meier, and W. Stricker, Rev. Sci. Instrum. 65(9), 2908 (1994).

${ }^{29}$ F. Xu, P. B. Sunderland, and G. M. Faeth, Combust. Flame 108(4), 471 (1997).

${ }^{30}$ F. Xu, K. C. Lin, and G. M. Faeth, Combust. Flame 115(1-2), 195 (1998).

${ }^{31}$ C. D. Carter, G. B. King, and N. M. Laurendeau, Rev. Sci. Instrum. 60(8), 2606 (1989).

${ }^{32}$ F. Migliorini, S. Deiuliis, F. Cignoli, and G. Zizak, Combust. Flame 153(3), 384 (2008).

${ }^{33}$ F. N. Egolfopoulos, N. Hansen, Y. Ju, K. Kohse-Höinghaus, C. K. Law, and J. Qi, Prog. Energy Combust. Sci. 43, 36 (2014).

${ }^{34}$ C. S. McEnally, L. D. Pfefferle, B. Atakan, and K. Kohse-Höinghaus, Prog. Energy Combust. Sci. 32(3), 247 (2006).

${ }^{35}$ A. Mcllroy, T. D. Hain, H. A. Michelsen, and T. A. Cool, Proc. Combust. Inst. 28(2), 1647 (2000).

${ }^{36}$ T. A. Cool, A. Mcllroy, F. Qi, P. R. Westmoreland, L. Poisson, D. S. Peterka, and M. Ahmed, Rev. Sci. Instrum. 76(9), 094102 (2005). 
${ }^{37}$ K. Wohl, Symp. (Int.) Combust. 4(1), 68 (1953).

${ }^{38}$ L. P. H. de Goey, J. A. van Oijen, V. N. Kornilov, and J. H. M. ten Thije Boonkkamp, Proc. Combust. Inst. 33(1), 863 (2011).

${ }^{39}$ I. Schoegl, Combust. Flame 159(9), 2817 (2012).

${ }^{40}$ C. Weise, A. Faccinetto, S. Kluge, T. Kasper, H. Wiggers, C. Schulz, I. Wlokas, and A. Kempf, Combust. Theory Modell. 17(3), 504 (2013).

${ }^{41}$ R. K. Hanson, Proc. Combust. Inst. 33, 1 (2011).

${ }^{42}$ B. Axelsson, R. Collin, and P.-E. Bengtsson, Appl. Opt. 39(21), 3683 (2000).

${ }^{43}$ C. Douté, J. L. Delfau, R. Akrich, and C. Vovelle, Combust. Sci. Technol. 106(4-6), 327 (1995).

${ }^{44}$ B. Zhao, Z. Yang, J. Wang, M. V. Johnston, and H. Wang, Aerosol Sci. Technol. 37(8), 611 (2003).

${ }^{45}$ B. Zhao, Z. Yang, M. V. Johnston, H. Wang, A. S. Wexler, M. Balthasar, and M. Kraft, Combust. Flame 133(1-2), 173 (2003).

${ }^{46}$ P. Desgroux, X. Mercier, B. Lefort, R. Lemaire, E. Therssen, and J. F. Pauwels, Combust. Flame 155(1-2), 289 (2008).

${ }^{47}$ S. De Iuliis, S. Maffi, F. Migliorini, F. Cignoli, and G. Zizak, Appl. Phys. B 106(3), 707 (2012).

${ }^{48}$ T. Mouton, X. Mercier, M. Wartel, N. Lamoureux, and P. Desgroux, Appl. Phys. B 112(3), 369 (2013).

${ }^{49}$ N. Hansen, M. Braun-Unkhoff, T. Kathrotia, A. Lucassen, and B. Yang, Proc. Combust. Inst. 35(1), 771 (2015)

${ }^{50}$ F. Ossler, S. E. Canton, L. R. Wallenberg, A. Engdahl, S. Seifert, J. P. Hessler, and R. S. Tranter, Carbon 96, 782 (2016).

${ }^{51}$ W. Yu, G. Chen, Z. Huang, Z. Chen, J. Gong, J. Yang, Z. Wang, and F. Qi, Combust. Flame 159(1), 44 (2012).

${ }^{52}$ A. Bohlin and C. J. Kliewer, J. Phys. Chem. Lett. 6(4), 643 (2015).

${ }^{53}$ A. D'Alessio, A. D'Anna, A. D'Orsi, P. Minutolo, R. Barbella, and A. Ciajolo, Symp. (Int.) Combust. 24(1), 973 (1992).

${ }^{54}$ A. D'Anna, A. Violi, A. D'Alessio, and A. F. Sarofim, Combust. Flame 127(1-2), 1995 (2001).

${ }^{55}$ M. M. Maricq, Combust. Flame 144(4), 730 (2006).

${ }^{56}$ A. D. Abid, N. Heinz, E. D. Tolmachoff, D. J. Phares, C. S. Campbell, and H. Wang, Combust. Flame 154(4), 775 (2008).

${ }^{57}$ H. Bladh, J. Johnsson, N. E. Olofsson, A. Bohlin, and P. E. Bengtsson, Proc. Combust. Inst. 33(1), 641 (2011).

${ }^{58}$ H. Bladh, N.-E. Olofsson, T. Mouton, J. Simonsson, X. Mercier, A. Faccinetto, P.-E. Bengtsson, and P. Desgroux, Proc. Combust. Inst. 35(2), 1843 (2015).

${ }^{59}$ M. Schenk, S. Lieb, H. Vieker, A. Beyer, A. Gölzhäuser, H. Wang, and K. Kohse-Höinghaus, Proc. Combust. Inst. 35(2), 1879 (2015).

${ }^{60}$ C. Russo, A. Tregrossi, and A. Ciajolo, Proc. Combust. Inst. 35(2), 1803 (2015).

${ }^{61}$ K. O. Johansson, T. Dillstrom, M. Monti, F. El Gabaly, M. F. Campbell, P. E. Schrader, D. M. Popolan-Vaida, N. K. Richards-Henderson, K. R. Wilson, A. Violi, and H. A. Michelsen, Proc. Natl. Acad. Sci. U. S. A. 113(30), 8374 (2016)

${ }^{62}$ K. O. Johansson, T. Dillstrom, P. Elvati, M. F. Campbell, P. E. Schrader, D. M. Popolan-Vaida, N. K. Richards-Henderson, K. R. Wilson, A. Violi, and H. A. Michelsen, Proc. Combust. Inst. 36(1), 799 (2017).

${ }^{63}$ E. Paganini, G. Mariotti, S. Gasperetti, C. Vallebona, L. Predolin, E. Muré, V. Palleschi, A. Salvetti, and E. Tognoni, Spectrochim. Acta, Part B 63(2), 191 (2008).
${ }^{64}$ A. Bohlin, B. D. Patterson, and C. J. Kliewer, J. Chem. Phys. 138(8), 081102 (2013).

${ }^{65}$ A. Bohlin, M. Mann, B. D. Patterson, A. Dreizler, and C. J. Kliewer, Proc. Combust. Inst. 35(3), 3723 (2015).

${ }^{66}$ Reaction Design, San Diego, 2013.

${ }^{67}$ R. J. Kee, F. M. Rupley, J. A. Miller, M. E. Coltrin, J. F. Grcar, E. Meeks, H. K. Moffat, A. E. Lutz, G. Dixon-Lewis, M. D. Smooke, J. Warnatz, G. H. Evans, R. S. Larson, R. E. Mitchell, L. R. Petzold, W. C. Reynolds, M. Caracotsios, W. E. Stewart, P. Glarborg, C. Wang, and O. Adigun, "PREMIX: A program for modeling steady, laminar, one-dimensional premixed flames," Reaction Design Report No. PRE-036-1, 2000.

${ }^{68}$ H. Wang, X. You, A. V. Joshi, S. G. Davis, A. Laskin, F. Egolfopoulos, and C. K. Law, USC Mech version II, High-temperature combustion reaction model of $\mathrm{H} 2 / \mathrm{CO} / \mathrm{C} 1-\mathrm{C} 4$ compounds, University of Southern California, Los Angeles, CA, 2007.

${ }^{69}$ K. J. Bosschaart, M. Versluis, R. Knikker, T. H. Vandermeer, K. R. A. M. Schreel, L. P. H. De Goey, and A. A. Van Steenhoven, Combust. Sci. Technol. 169(1), 69 (2001).

${ }^{70}$ S. A. Skeen, H. A. Michelsen, K. R. Wilson, D. M. Popolan, A. Violi, and N. Hansen, J. Aerosol Sci. 58, 86 (2013).

${ }^{71}$ K. O. Johansson, J. Y. W. Lai, S. A. Skeen, D. M. Popolan-Vaida, K. R. Wilson, N. Hansen, A. Violi, and H. A. Michelsen, Proc. Combust. Inst. 35, 1819 (2015).

${ }^{72}$ K. O. Johansson, J. Zádor, P. Elvati, M. F. Campbell, P. E. Schrader, N. K. Richards-Henderson, K. R. Wilson, A. Violi, and H. A. Michelsen, J. Phys. Chem. A 121, 4475 (2017).

${ }^{73}$ X. Zhang, K. A. Smith, D. R. Worsnop, J. L. Jimenez, J. T. Jayne, C. E. Kolb, J. Morris, and P. Davidovits, Aerosol Sci. Technol. 38(6), 619 (2004).

${ }^{74}$ J. M. Headrick, P. E. Schrader, and H. A. Michelsen, J. Aerosol Sci. 58, 158 (2013).

${ }^{75}$ E. L. Knuth, Combust. Flame 103(3), 171 (1995).

${ }^{76}$ S. E. Stein and A. Fahr, J. Phys. Chem. 89(17), 3714 (1985).

${ }^{77}$ N. Hansen, S. J. Klippenstein, P. R. Westmoreland, T. Kasper, K. Kohse-Hoinghaus, J. Wang, and T. A. Cool, Phys. Chem. Chem. Phys. 10(3), 366 (2008).

${ }^{78}$ M. A. Dansson, M. Boisselle, M. A. Linne, and H. A. Michelsen, Appl. Opt. 46(33), 8095 (2007).

${ }^{79}$ H. A. Michelsen, P. E. Schrader, and F. Goulay, Carbon 48(8), 2175 (2010).

${ }^{80}$ F. Goulay, P. E. Schrader, X. López-Yglesias, and H. A. Michelsen, Appl. Phys. B 112(3), 287 (2013).

${ }^{81}$ M. F. Campbell, A. Bohlin, P. E. Schrader, R. P. Bambha, C. J. Kliewer, K. O. Johansson, and H. A. Michelsen, Rev. Sci. Instrum. 87(11), 115114 (2016).

${ }^{82}$ X. López-Yglesias, P. E. Schrader, and H. A. Michelsen, J. Aerosol Sci. 75, 43 (2014)

${ }^{83}$ K. O. Johansson, F. El Gabaly, P. E. Schrader, M. F. Campbell, and H. A. Michelsen, "Evolution of maturity levels of the particle surface and bulk during soot growth and oxidation in a flame," Aerosol Sci. Technol. (published online).

${ }^{84}$ T. C. Williams, C. R. Shaddix, K. A. Jensen, and J. M. Suo-Anttila, Int. J. Heat Mass Transfer 50(7-8), 1616 (2007).

${ }^{85}$ C. Schulz, B. F. Kock, M. Hofmann, H. Michelsen, S. Will, B. Bougie, R. Suntz, and G. Smallwood, Appl. Phys. B 83(3), 333 (2006). 